$$
\begin{aligned}
& \text { شناسابى جلبك هاى رشته اى رودخانه باليخلو در استان اردبيل و گزارش جههارَّونه جديد } \\
& \text { براى فلور جلبكى ابران. }
\end{aligned}
$$

$$
\text { وازمهاى كليدى. ايىليت، إيىفيت، آرايهشناسى، سيانوباكترى، يامجى }
$$

\title{
Identification of filamentous algae of the Balikhli River in the Ardabil Province and four new species records for algal flora of Iran
}

\section{Jamileh Panahy Mirzahasnlou ${ }^{1}$, Taher Nejadsattari ${ }^{2}$, Zohreh Ramezanpour ${ }^{3}$, Javid Imanpour Namin ${ }^{4} \&$ Younes Asri ${ }^{5}$}

${ }^{1}$ Department of Biology, Faculty of Basic Science, Gonbad Kavous University, Gonbad Kavous, Iran; ${ }^{2}$ Department of Biology, College of Science, Tehran Science and Research Branch, Islamic Azad University, Tehran, Iran; ${ }^{3}$ International Sturgeon Research Institute, Agraicultural research education and extension organization (AREEO), Rasht-Iran, PO. Box. 41635-3464; ${ }^{4}$ Department of Fishery, Faculty of Natural Resources, University of Guilan, Some Sara, Guilan, Iran; ${ }^{5}$ Division of Botany, Research Institute of Forests and Rangelands, Agricultural Research, Education and Extension Organization, Tehran, Iran. Correspondent author: Jamileh Panahy Mirzahasanlou, panahi@gonbad.ac.ir

\begin{abstract}
Algae are the most important group of organisms which considerably affect the water quality. Although algae constitute one of the fundamental parts of the aquatic food chains, only few researches deal with the freshwater algae of Iran. Filamentous algae are important components of the river vegetation. The Balikhlou River is utilized as a source to obtain drinking water for the city of Ardabil, therefore, the algae flora of this river was studied and a total number of 18 taxa of filamentous algae were determined, of which nine species were belonged to the Cyanophyceae class of Cyanobacteriae, while five speciesof which were belonged to the Chlorophyta. In addition, four species were recorded for the first time from Iran, i.e., Audouinella eugenea, Arthrospira gigantea, Homoeothrix janthina and Tychonema bourrellyi.
\end{abstract}

Key words. Epilthic, Epiphytic, Taxonomy, Cyanobacteria, Yamchi

$$
\text { *د كتر طاهر نزّادستارى به ديار باقى شتافتهاند. يادشان را كرامى مىداريم. }
$$


رودخانه به عنوان منبع آب شرب شهر اردبيل استفاده مىشـود

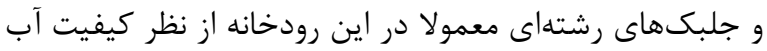

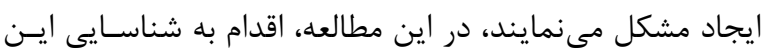

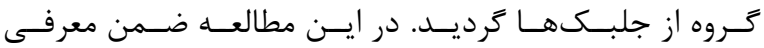

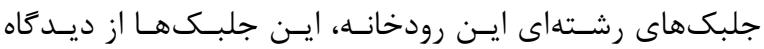
سيستماتيك نيز مورد بررسى قرار خرفتند.

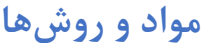

رودخانه باليخلو در جنـوب غربسى شـهر اردبيـل در محسدوده

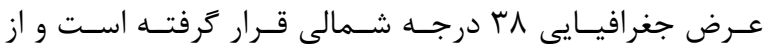

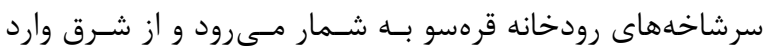
شهر اردبيل مىشود. سد يامجى با هدف بهـرهذيـرى از جريـان

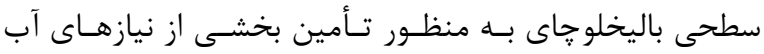

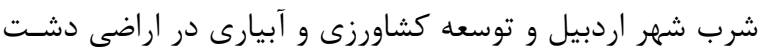

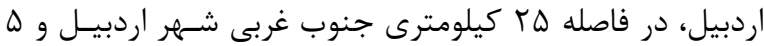
كيلومترى شمال شرقى شهر نير، بر روى بـاليخلوجـاى احسداث

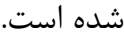
به منظور شناسايى جلبكهاى اين رودخانسه، نمونسهــا طـى

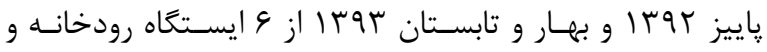

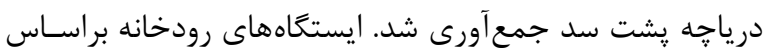
نزديكى به منابع آلودگى و وجود سد انتخاب شدند (جـدول () ).

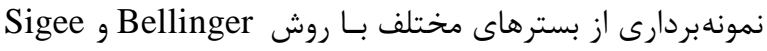
(2010) انجام شد. نمونههاى إيى ليتيك با استفاده از مسواى از

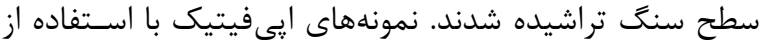

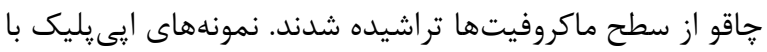

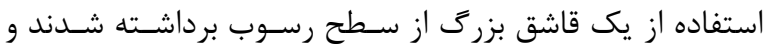

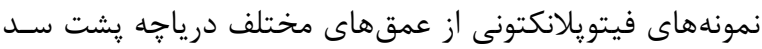

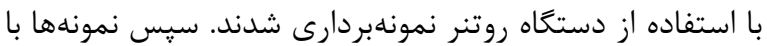

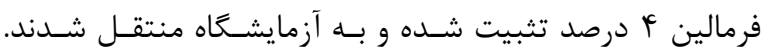

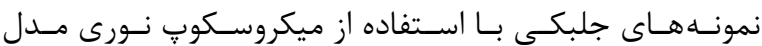

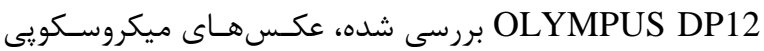

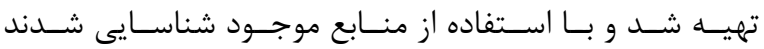
Prescott, 1970; Tiffany \& Britton, 1971; ) Crossdale, 1973; Skinner \& Entwisle, 2001; Lokhorst, 2003; Wehr \& Sheath, 2003; Skinner \& Entwisle, 2004; John et al., 2005; Komarek, 2005; (Gonzales \& Gonzales, 2010; Sili et al., 2012 ردهبنــدى تونسهـهـاى شناسـايى شــده بــا اسـتفاده از سـايت

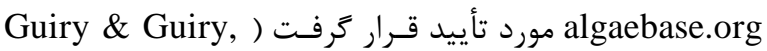
. 2018
مقله

فرم رشتهاى از اشكال ريخت شناسانه رايج در ميان جلبكها

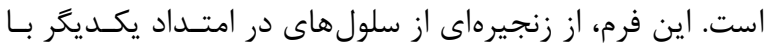

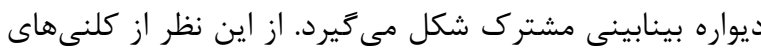

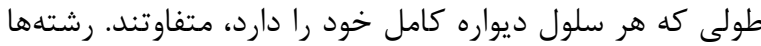
ممكن است يكرديفى يا جندرديفى باشند، همجنـين رشـتهها

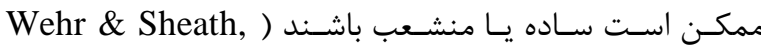

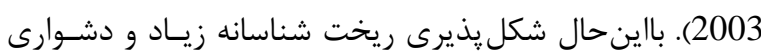

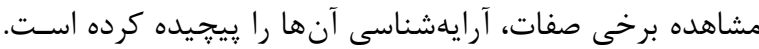
اين گروه از جلبكها به كروه آرايهشناختى خاصى تعلق ندان آندارند.

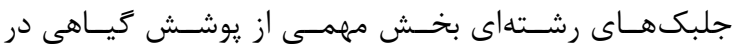

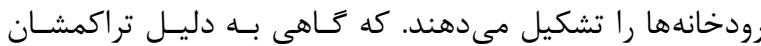

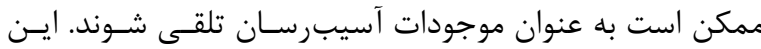

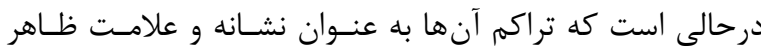

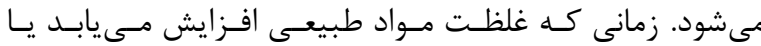
زمانى كه تركيبات سنتتيك غيرطبيعى در محيط آزاد مي شونداند،

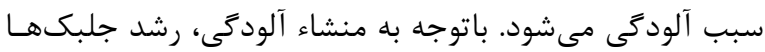

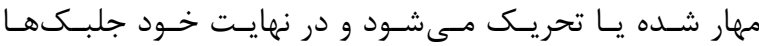
مسئلهسـاز مسىشـوند (Bilgrami \& Saha, 2002). بنـابراين شناسايى گروههاى مختلف جلبكى (شامل جلبكهاى رشتهاى)

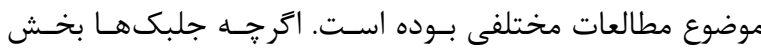

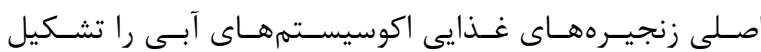

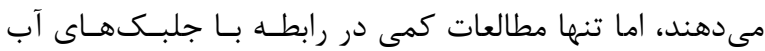

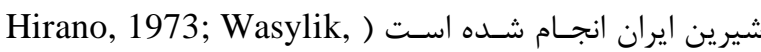
1975; Compere, 1981 مختلف جلبكى در مناطقى از ايران مورد توجه قرار كرفته و بـهـ

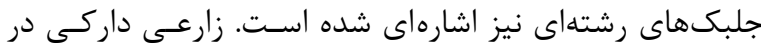

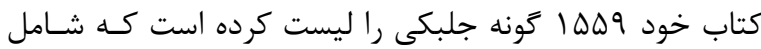
جلبكهاى رشتهاى نيـز مسىشود (Zarei Darki, 2011). در جر سالهاى اخير مطالعات קندى نيز به صـورت گسســـه صـورت

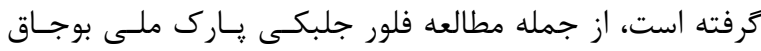
(Noroozi et al., 2009)، جلبكهاى رودخانه سياه درويشـان كـــيلان (Faghir \& Shafii, 2013) و مطالعــه تركيـبـ

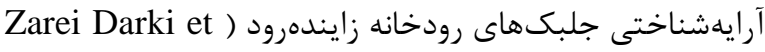

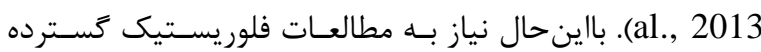

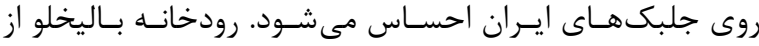

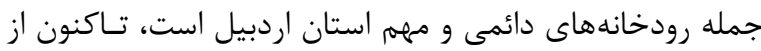

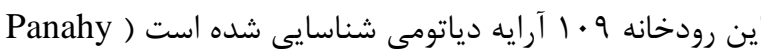

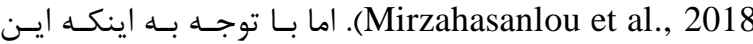


جدول ا- ايستگاههاى نمونهبردارى رودخانه باليخلو

Table 1. Sampling stations on Balikhli River.

\begin{tabular}{|c|c|c|c|c|}
\hline $\begin{array}{l}\text { No. of } \\
\text { Station }\end{array}$ & Location & $\begin{array}{c}\text { Latitude and } \\
\text { Langitude }\end{array}$ & Substrate & Vegetation \\
\hline 1 & $\begin{array}{l}\text { Ilanjigh region: Entry of the } \\
\text { Balikhli River to the Ardabil } \\
\text { province near village Ilanjigh. }\end{array}$ & $\begin{array}{l}38^{\circ} \cdot 0^{\prime} \cdot 8 \cdot 3^{\prime \prime} \mathrm{N} \\
47^{\circ} \cdot 55^{\prime} \cdot 41 \cdot 4^{\prime \prime}\end{array}$ & $\begin{array}{l}\text { small cobbles, } \\
\text { clay and silt }\end{array}$ & $\begin{array}{c}\text { Batrachium trichophyllum (Chaix) Bosch., } \\
\text { Epilobium hirsutum L., Lemna minor L., } \\
\text { Lythrum salicaria L., Nasturtium officinale } \\
\text { (L.) R. Br., Typha sp., Veronica anagalis } \\
\text { aquatic L. }\end{array}$ \\
\hline 2 & $\begin{array}{l}\text { Borjlou bridge; Downstream of } \\
\text { waste water inflow of Borjlou } \\
\text { village and hot mineral water } \\
\text { springs. }\end{array}$ & $\begin{array}{c}38^{\circ} .0^{\prime} \cdot 52 \cdot 3^{\prime \prime} \mathrm{N} \\
47^{\circ} .55^{\prime} \cdot 41.4^{\prime \prime} \mathrm{E}\end{array}$ & $\begin{array}{l}\text { large cobbles } \\
\text { and sand }\end{array}$ & Scirpus sp., little vegetation on banksides. \\
\hline 3 & $\begin{array}{l}\text { Sagharlou bridge: Downstream of } \\
\text { the confluence of Aghlaghan } \\
\text { River and Balikhli River. }\end{array}$ & $\begin{array}{c}38^{\circ} .1^{\prime} \cdot 13 \cdot 5^{\prime \prime} \mathrm{N} \\
48^{\circ} .11^{\prime} \cdot 13^{\prime \prime} \mathrm{E}\end{array}$ & clay and silt & $\begin{array}{l}\text { Batrachium trichophyllum (Chaix) Bosch., } \\
\text { Lemna minor L., Lythrum salicaria L., } \\
\text { Myriophyllum sp., Typha sp. }\end{array}$ \\
\hline 4 & $\begin{array}{l}\text { Downstream of the Yamchi dam, } \\
\text { with periodic fluctuations in } \\
\text { water volume. }\end{array}$ & $\begin{array}{l}39^{\circ} \cdot 5^{\prime} \cdot 0 \cdot 5^{\prime \prime} \mathrm{N} \\
48^{\circ} \cdot 5^{\prime} \cdot 25 \cdot 9^{\prime \prime} \mathrm{E}\end{array}$ & $\begin{array}{l}\text { large cobble, } \\
\text { gravel }\end{array}$ & Myriophyllum sp. \\
\hline 5 & Almas bridge. & $\begin{array}{l}38^{\circ} \cdot 9^{\prime} \cdot 17 \cdot 9^{\prime \prime} \mathrm{N} \\
48^{\circ} \cdot 11.344^{\prime \prime} \mathrm{E}\end{array}$ & $\begin{array}{l}\text { gravel and } \\
\text { clay. }\end{array}$ & $\begin{array}{l}\text { Batrachium trichophyllum (Chaix) Bosch., } \\
\text { Scirpus sp., Myriophyllum sp., Potamogeton } \\
\text { crispus L. }\end{array}$ \\
\hline 6 & Entry of Ardabil. & $\begin{array}{c}38^{\circ} \cdot 13^{\prime} \cdot 18^{\prime \prime} \mathrm{N} \\
48^{\circ} \cdot 16^{\prime} \cdot 0 " \mathrm{E}\end{array}$ & $\begin{array}{c}\text { large cobble, } \\
\text { gravel }\end{array}$ & $\begin{array}{c}\text { Scirpus sp., Myriophyllum sp., Sparganium } \\
\text { erectum L. }\end{array}$ \\
\hline
\end{tabular}

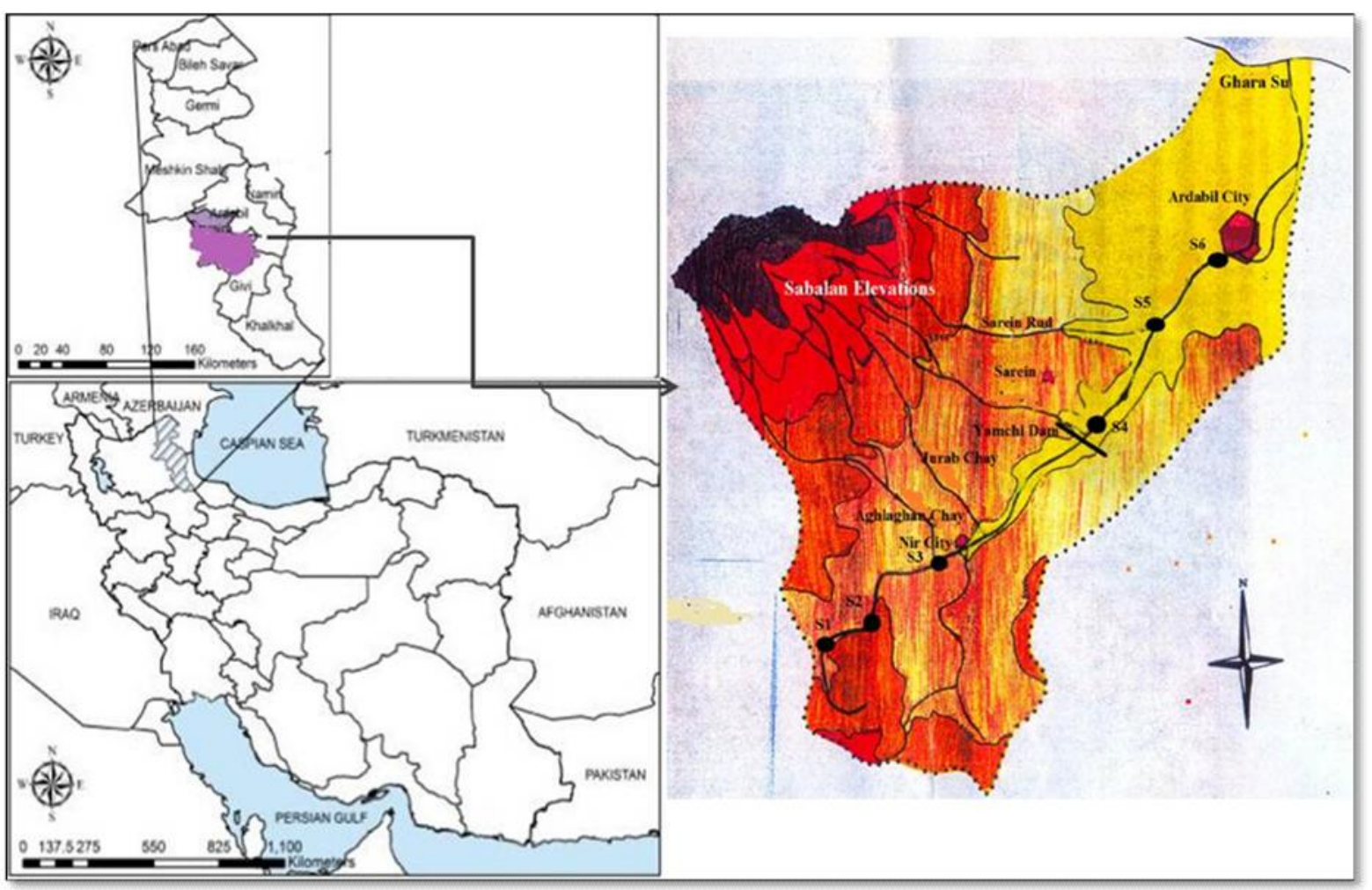

شكل ا- موقعيت ايستگاههاى نمونهبردارى روى رودخانه باليخلو.

Fig. 1. Location of sampling stations on Balikhli River. 


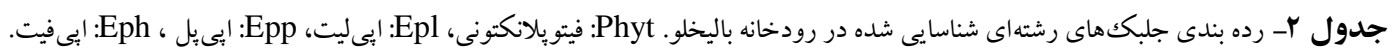

Table 2. The classification of Filamentous algae identified in Balikhli River. Phyt: Phytoplanktonic, Epl: Epilithic, Epp: Epipelic, Eph: Epiphytic.

\begin{tabular}{|c|c|c|c|c|}
\hline نام علمى & Phyt & Epl & Epp & Eph \\
\hline \multicolumn{5}{|l|}{ Charophyta: Conjugatophyceae } \\
\hline Spirogyra sp. & - & + & + & - \\
\hline \multicolumn{5}{|l|}{ Chlorophyta: Chlorophyceae } \\
\hline Oedogonium sp. & - & + & + & + \\
\hline Stigeoclonium helveticum Vischer & - & + & + & + \\
\hline \multicolumn{5}{|l|}{ Chlorophyta: Ulvophyceae } \\
\hline Cladophora glomerata (Linnaeus) Kutzing & - & + & + & - \\
\hline Ulothrix tenuissima Kutzing & - & + & - & + \\
\hline Ulva intestinalis Linnaeus & - & + & - & - \\
\hline \multicolumn{5}{|l|}{ Cyanobacteria: Cyanophyceae } \\
\hline Anabaenopsis elenkinii V.V. Miller & + & - & - & - \\
\hline Aphanizomenon flosaquae Ralfs ex Bornet \& Flahault & + & - & - & - \\
\hline Arthrospira gigantean (Schmidle) Anagnostidis & + & + & + & + \\
\hline Homoeothrix janthina (Bornet \& Flahault) Starmach & - & + & - & + \\
\hline Oscillatoria limosa $\mathrm{C}$. Agardh ex Gomont & + & + & + & - \\
\hline Oscillatoria princeps Vaucher ex Gomont & + & + & + & - \\
\hline Oscillatoria tenuis C.A.Agardh ex Gomont & + & + & + & - \\
\hline Planktolyngbya limnetica (Lemmermann) Komarkova-Legnrova \& Cronberg & + & - & - & - \\
\hline Tychonema bourrellyi (J.W.G. Lund) Anagnostidis \& Komarek & + & - & - & - \\
\hline \multicolumn{5}{|l|}{ Ochrophyta: Xanthophyceae } \\
\hline Tribonema viride Pascher & - & + & + & + \\
\hline Vaucheria sp. & - & + & + & - \\
\hline Rhodophyta: Florideophyceae & & & & \\
\hline Audouinella eugenea (Skuja) C-. C. Jao & - & + & - & - \\
\hline
\end{tabular}

يراكنش در منطقه مورد مطالعه: ايستخاههاى رودخانه بـاليخلو.

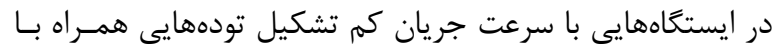

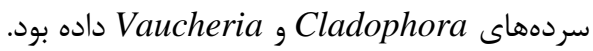

شاخه Chlorophyta

\section{Oedogonium sp.}

متعلق به تيره Oedogniaceae، راسـته Oedogoniales، رده

Chlorophyceae سلولهاى استوانهاى بعضىوقتها در انتهاى قدامى كمى يهنت

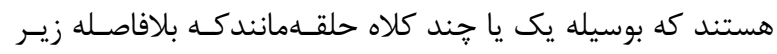
ديواره عرضى وجود دارد، مشخص مسىشـوند (شـكل r C T)، ايسن

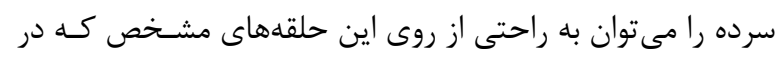

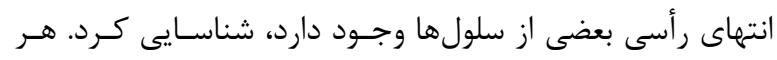

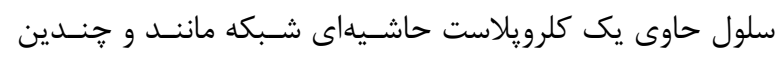

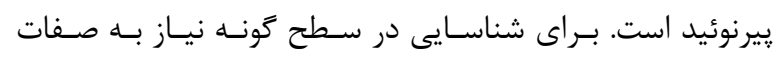

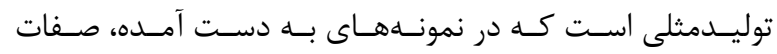

$$
\text { توليدمثلى مشاهده نشد. }
$$

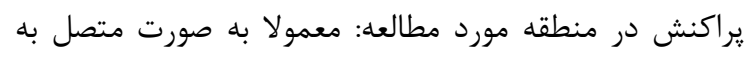

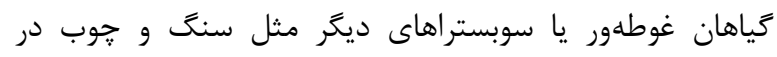

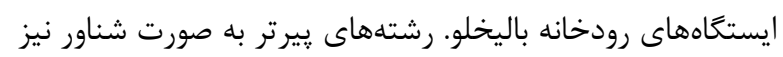

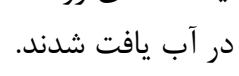

بلهطور كلى دراين بررسى \| آرايه جلبك رشتهاى (ها آرايه در

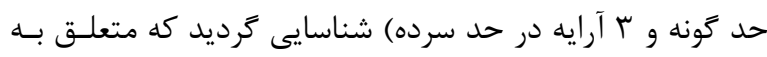

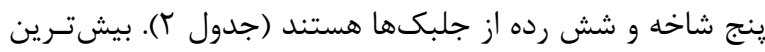

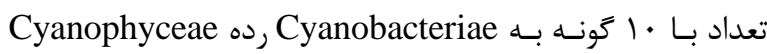
(جلبكهاى آبى- سبز) متعلق است. شاخههـاى Charophyta و Rhodophyta شناسايى شده به شرح زير هستند:

\section{شاخه Charophyta}

Spirogyra sp.

متعلق بـه تيـره Zygnemataceae، راسـته Zygnematales، رده Conjugatophyceae است. اين سرده را در فيلد مىتوان با لئا

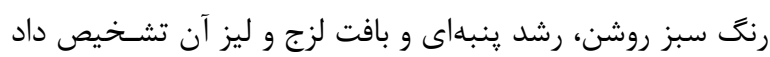

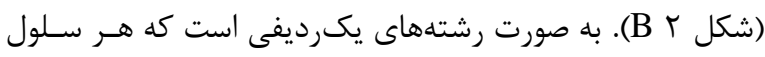

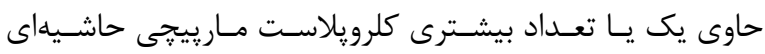

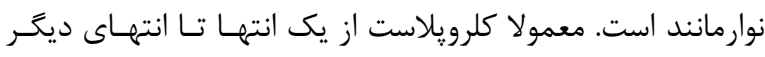
سلول جند يِيج مى خورد (شكل r A). همانند ديخـر سـردهـــاى تيره Zygnemataceae، شناسايى در سطح گونسه بـدون صـفات

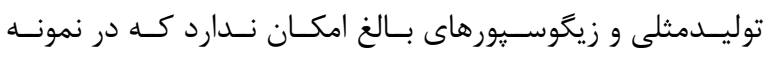
بردارىهاى انجام شده، صفات توليدمثلى مشاهده نشد. 


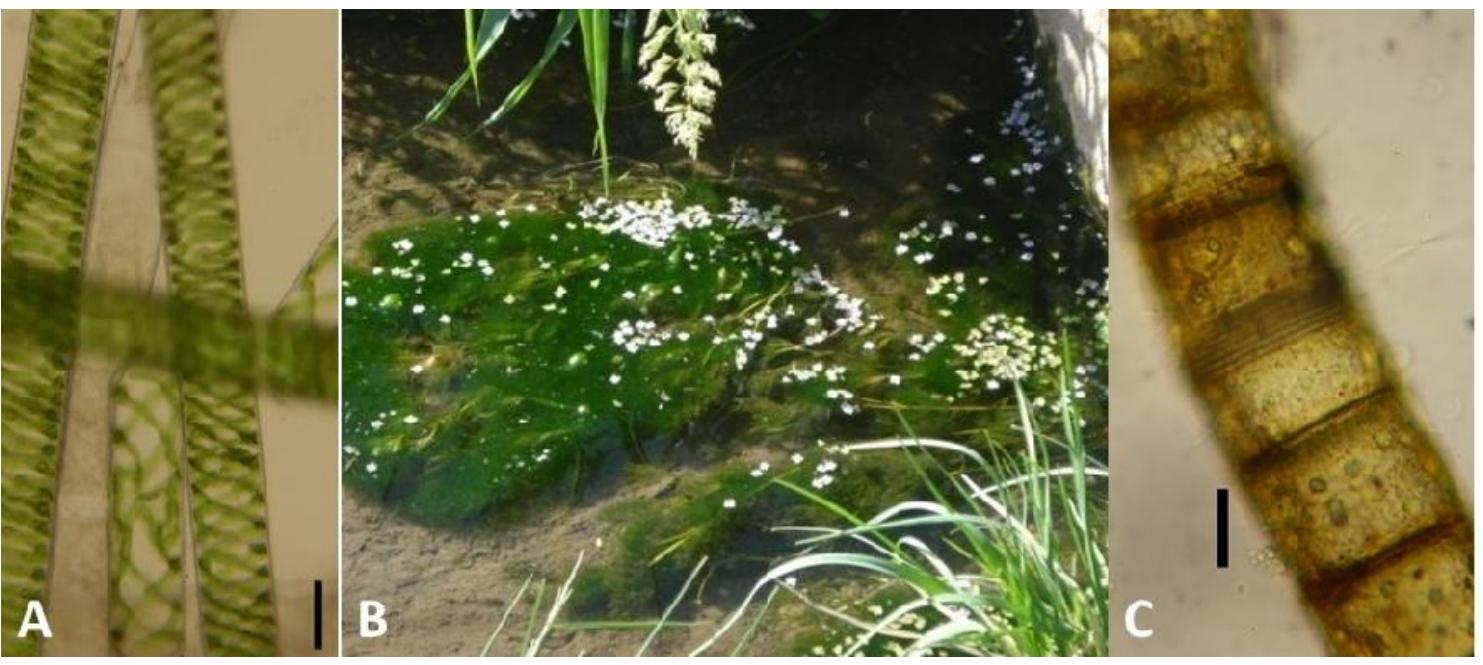

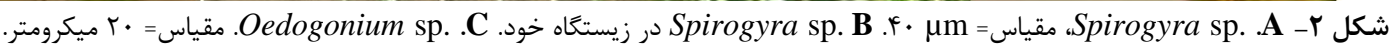

Fig. 2. A. Spirgyra sp. Bar= 40 m. B. Spirgyra sp. in its habitat. C. Oedogonium sp. Bar= $20 \mathrm{~m}$.

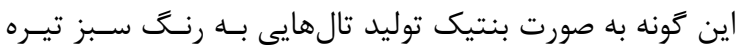

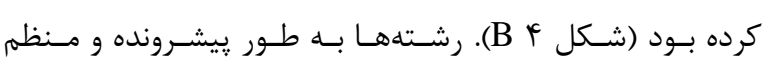

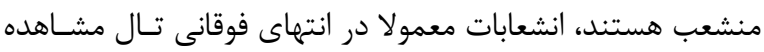

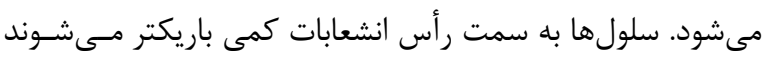

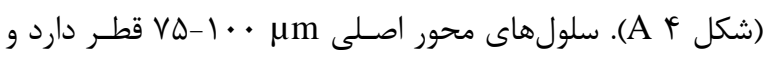

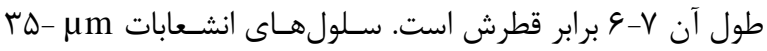

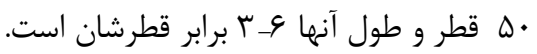

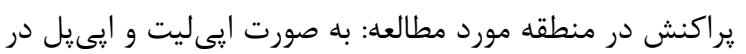

$$
\text { ايستغاههاى رودخانه باليخلو. }
$$

Ulothrix tenuissima Kutzing 1833

Syn: Ulothrix tenuis Kutzing

متعلق بـه تيــ Ulotrichaceae، راســه Ulotrichales، رده

Ulvophyceae

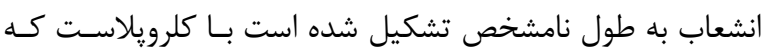

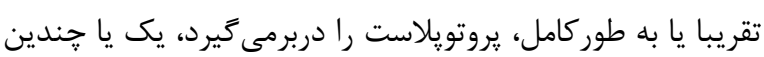

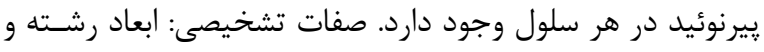
ابعاد سلول و وضعيت كلرويلاست.

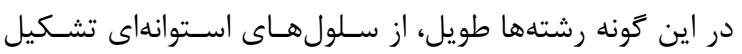

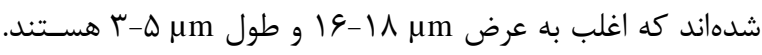

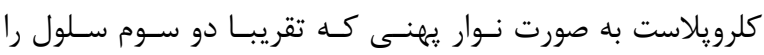

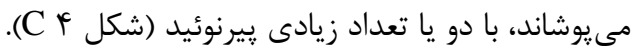

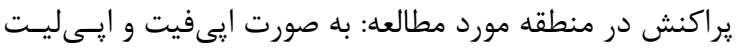

$$
\text { در ايستخاههاى رودخانه باليخلو. }
$$

Ulva intestinalis Linnaeus 1753

Syn: Enteromorpha intestinalis (Linnaeus) Nees

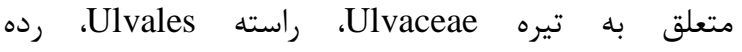
Ulvophyceae

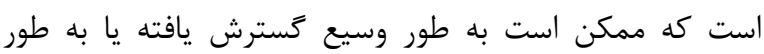

Stigeoclonium helveticum Vischer 1933

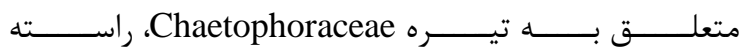
Chaetophorales

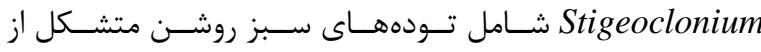
رشتهاى منشعب يكرديفى است كه سيستمهاى قائم و افقى يا خوابيده دارند (Michetti et al., 2010).

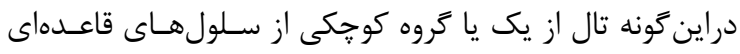

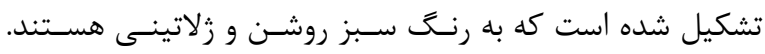

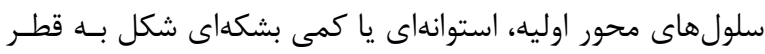

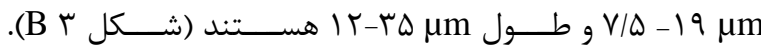

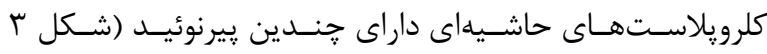
(C,D

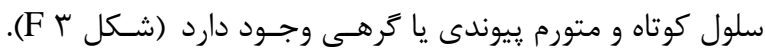

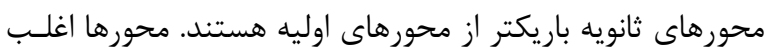

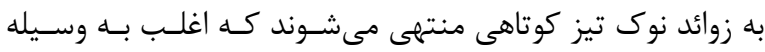

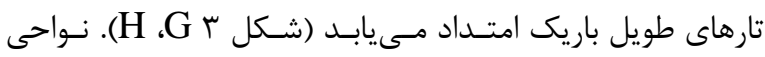

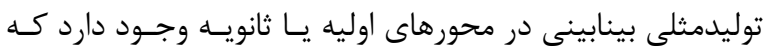

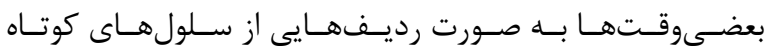
ديسكىشكل ديده مىشوند و بعضىوقتها به طور صليبى تقسيم

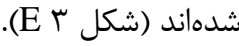
يراكنش در منطقه مورد مطالعه: از تمام بسترهاى ايستخاههاى (تشاى رودخانه باليخلو شناسايى كرديد.

Cladophora glomerata (Linnaeus) Kutzing 1843 متعلق به تيـره Cladophoraceae، راسـته Cladophorales،

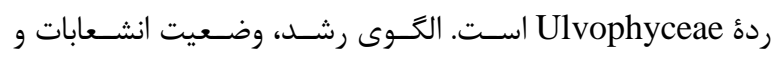
سلولها از صفات تشخيصى در سرده Cladophora هستند. 
ميانه رشته تشكيل مىشود اما نه در مجـاورت هتروسـيت. طـول

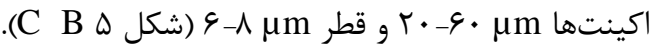

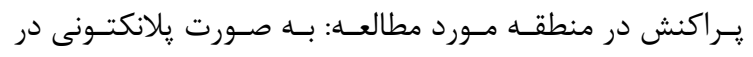
درياجه سد يامجى.

Homoeothrix janthina (Bornet \& Flahault) Starmach 1959

اين كَونه به عنوان كزارش جديدى بـراى ايـران در ايـن مقالـه ذكر مىشود.

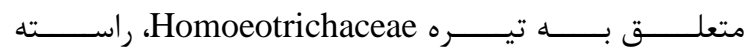
(Oscillatoriales

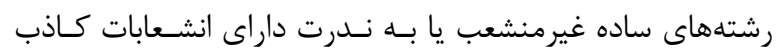

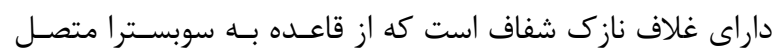

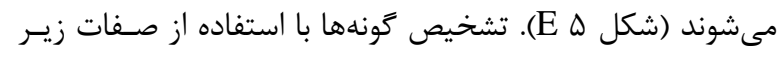

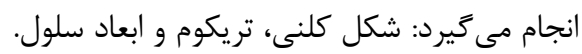

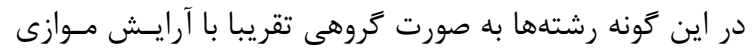

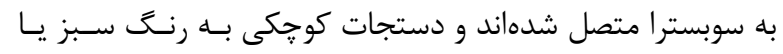

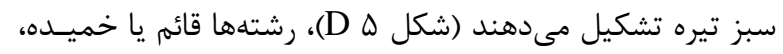

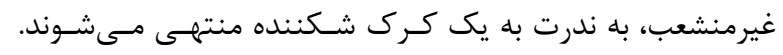

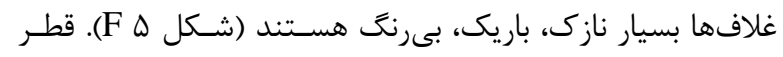

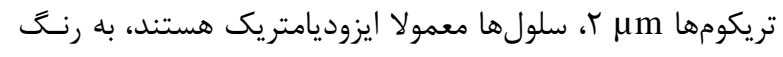

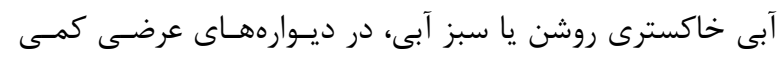

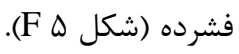
يـراكنش در منطقــه مــورد مطالعـه: بــه صـورت إيسىليـت در ايستخاههاى رودخانه باليخلو.

Arthrospira gigantea (Schmidle) Anagnostidis 1998

Syn: Spirulina gigantea Schmidle 1902

Oscillatoria gigantea (Schmidle) Compère 1974

اين زونه به عنوان ززارش جديدى بـراى ايـران در ايـن مقالـه ذكر مىشود.

متعلق به تيـه Microcoleaceae، راسـته Oscillatoriales،

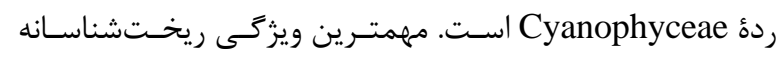

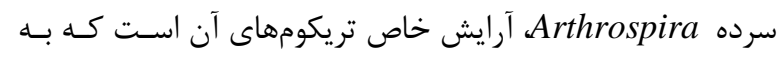

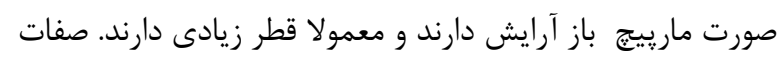

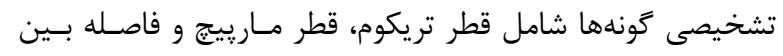

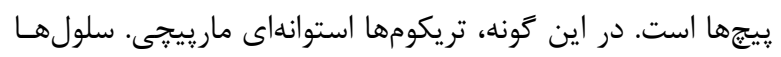

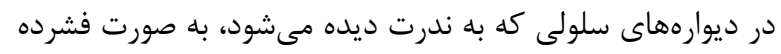

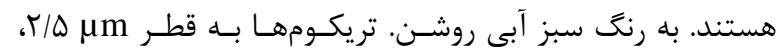

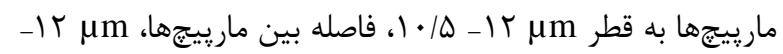
(ش $)$ V/D

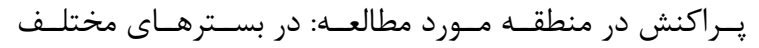
ايستخاههاى رودخانه باليخلو.
منظم لوبدار، گوهاى شكل، خطى، سرنيزهاى يا عميقا تقسيم شده

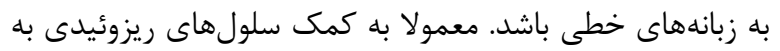

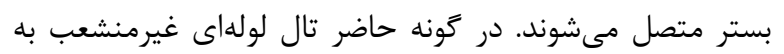

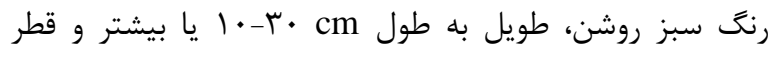

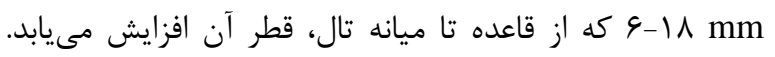

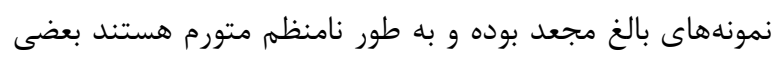

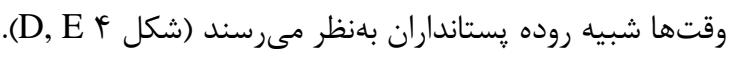

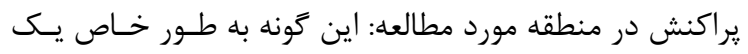

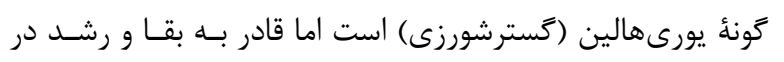

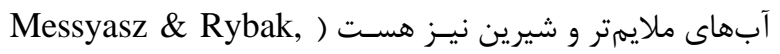

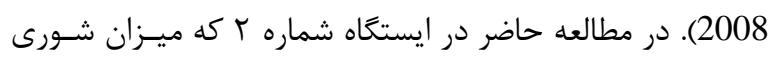

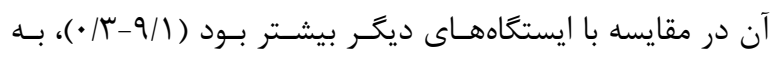
صورت إيىليت گسترش زيادى داشت.

\section{شاخه Cyanobacteria}

Anabaenopsis elenkinii V.V.Miller 1923

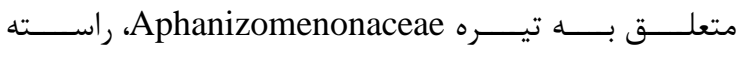
Nostocales Anabaenopsis

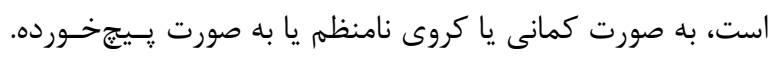

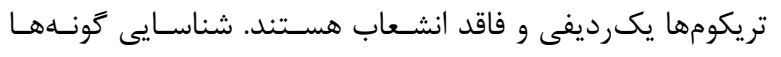

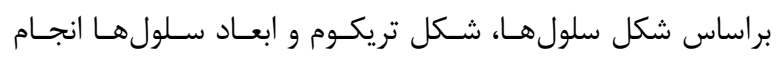
مى كيرد.

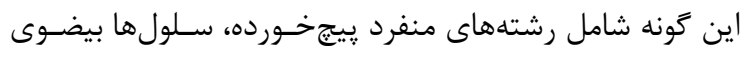

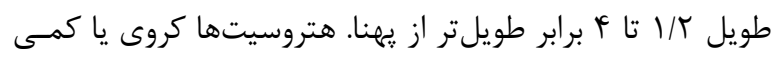

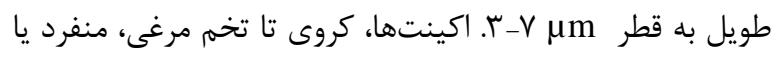

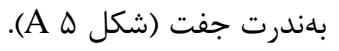

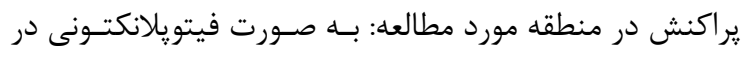
درياجه سد يامجى. Aphanizomenon flos aquae Ralfs ex Bornet \& Flahault

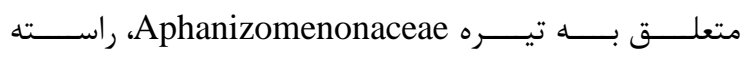
Nostocales Aphanizomenon

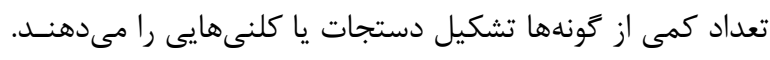

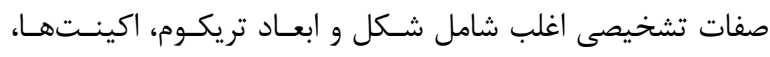

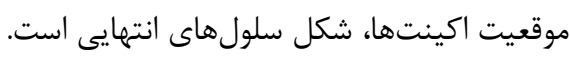

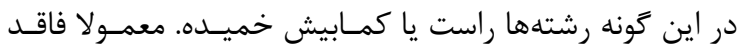

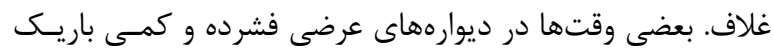

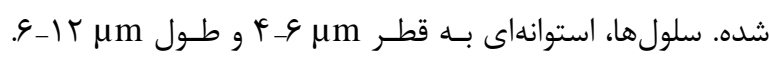

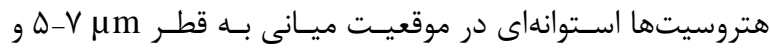

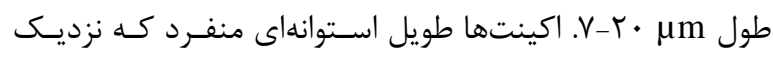




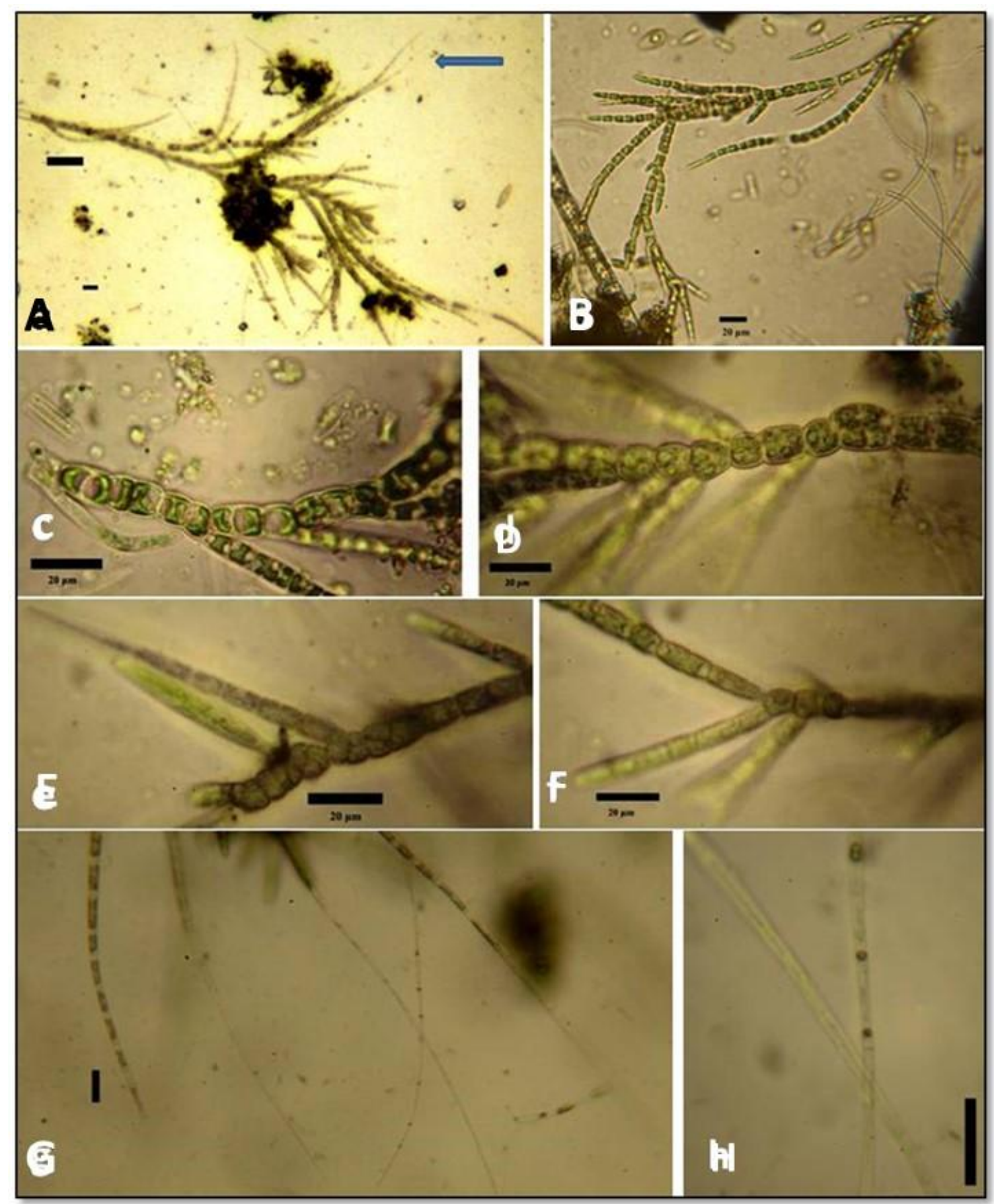

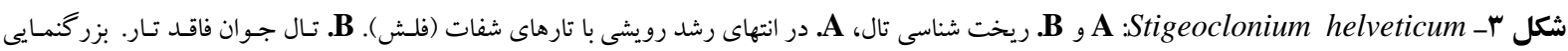
أ. 100 x

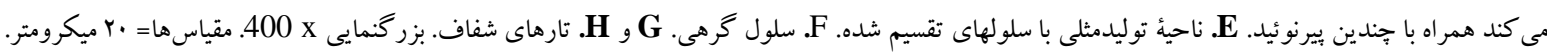

Fig. 3. Stigeoclonium helveticum: A, B. Thallus morphology. A. at the end of vegetative growth with hyaline hairs (arrow). B. vigorous thallus without any hair. Magnification 100x. C, D. chloroplast shape. C. ulothricoid shape not always seen. D. parietal plate like chloroplast covering most of the cell with several pyrenoids. E. reproductive region with divided cells. F. node cell. G, H. hyaline hair; magnification 400 x. Bars=20 m. 

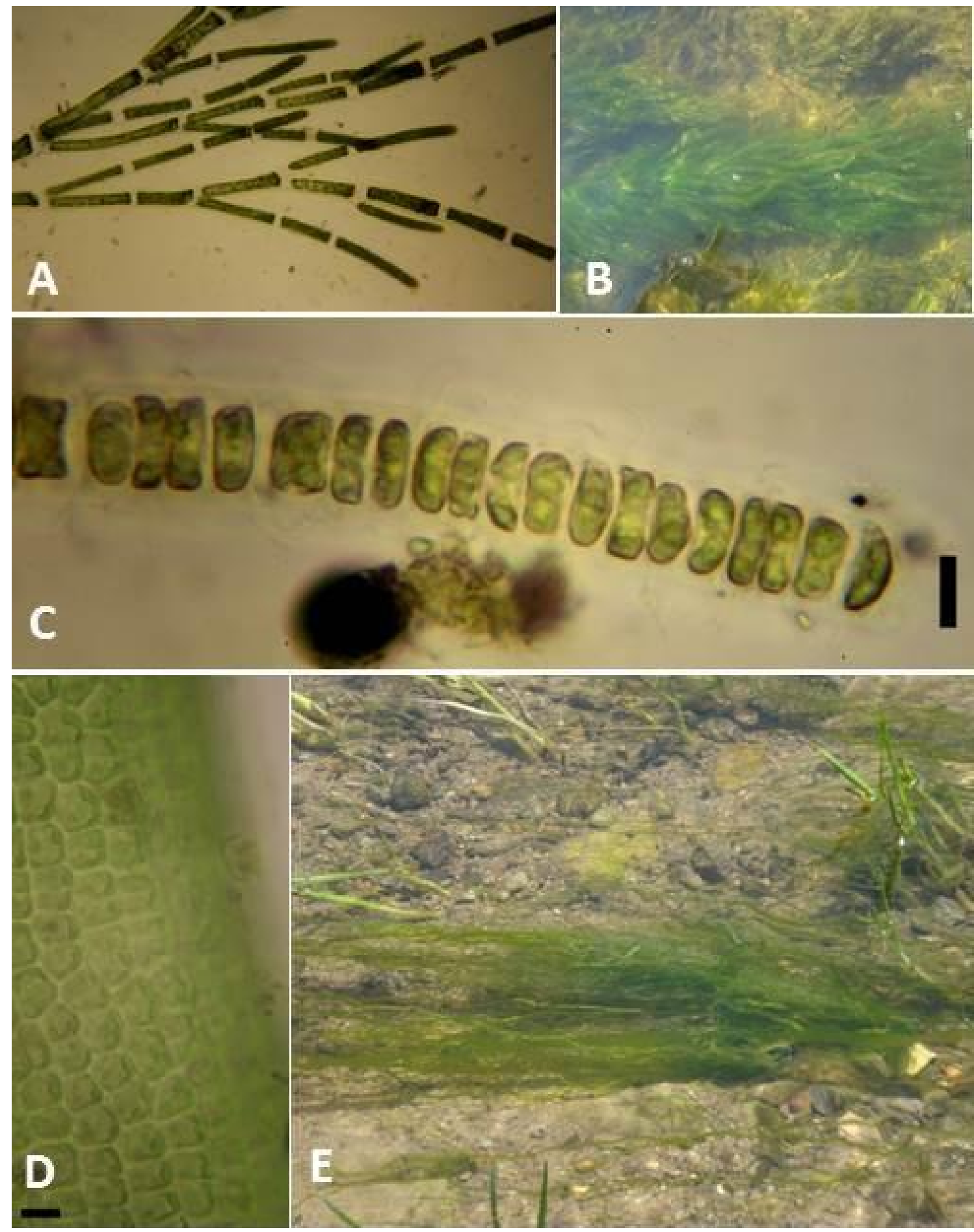

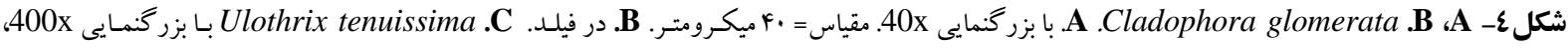

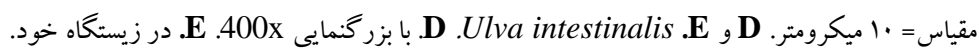

Fig. 4. A, B. Cladophora glomerata. A. with magnification of 40x. Bar=40 m. B. in field. C. Ulothrix tenuissima with magnification of 400x, Bar= 10 m. D, E. Ulva intestinalis. D. With magnification of 400x. E. In its habitat. 

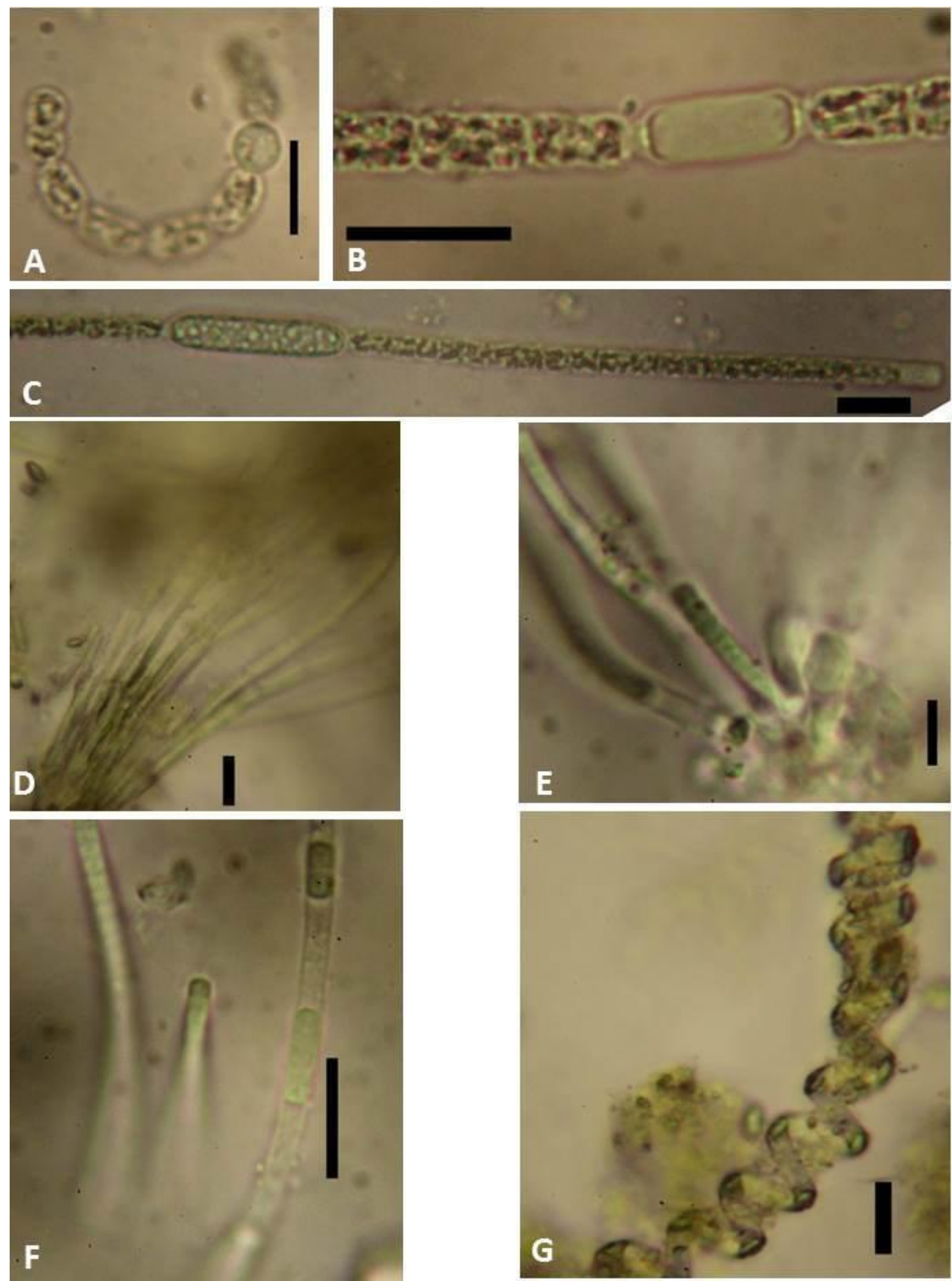

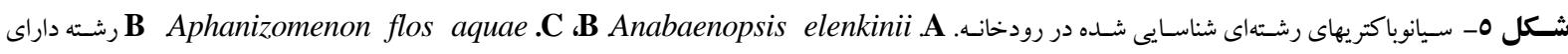

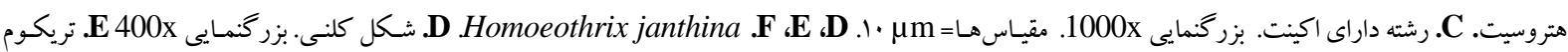

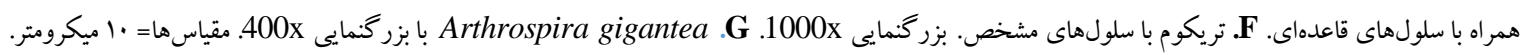

Fig. 5. Filamentous cyanobacteria identified in the river. A. Anabaenopsis elenkinii. B, C. Aphanizomenon flos aquae. B. Trichome with heterocyte. C. Trichome with Akinete. Magnification 1000x. bars= 10 m. D, E, F. Homoeothrix janthina. D. colony shape. Magnification 400x. E. trichome with basal cells. F. trichome with prominent cells. Magnification 1000x. G. Arthrospira gigantea with magnification of 400x. Bars $=10 \mathrm{~m}$. 
داراى رشـتهـــاى منفـــى اسـت بـا غــلاف Planktolyngbya

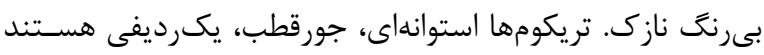

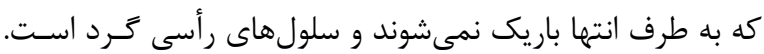

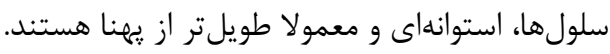

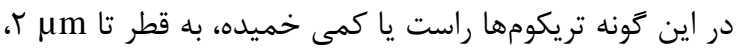

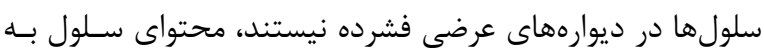
رنغ سبز-آبى روشن مايل به زرد (شكل 9 ع E).

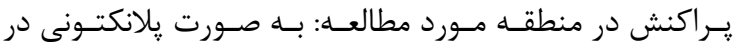
درياجه سد يامجى. Tychonema bourrellyi (J.W.G. Lund) Anagnostidis \& Komárek 1988

Syn: Oscillatoria bourrellyi J.W.G. Lund 1955

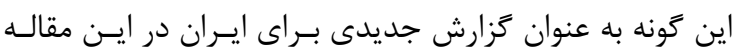

$$
\text { ذكر مىشود. }
$$

متعلق به تيـره Microcoleaceae، راسـته Oscillatoriales، رده Cyanophyceae است. در اين سرده، تريكومها منفرد يا بــه

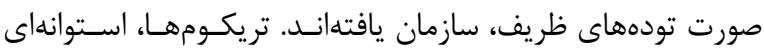
هستند فاقد غلاف يا داراى غلاف موسيلازى اختيارى نازك، فاقد

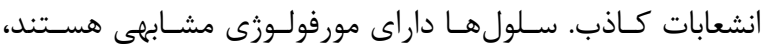

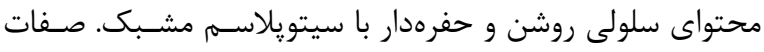

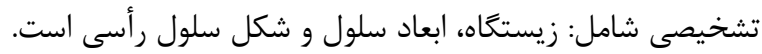

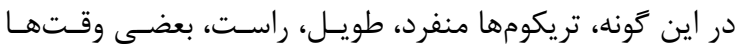

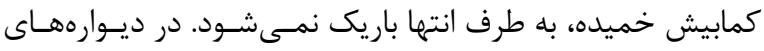

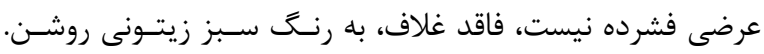

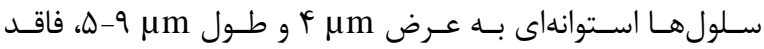

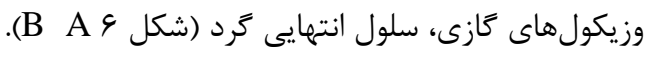

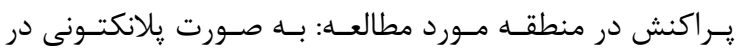
درياجه سد يامجى.

\section{شاخه Ochrophyta}

Tribonema viride Pascher 1925

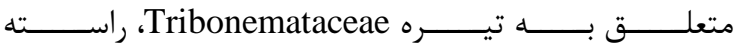

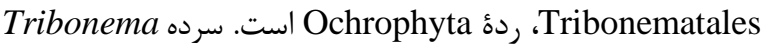

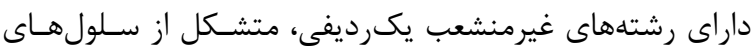

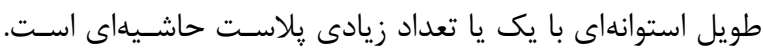
ديوارة سلولها داراى قطعات H شكل. صفات تشخيصى عبارتند

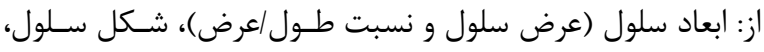

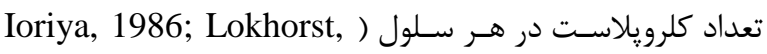

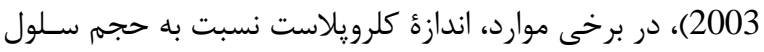

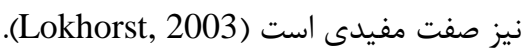

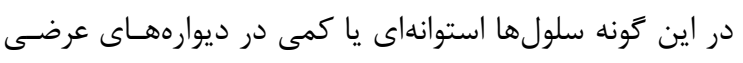

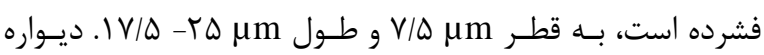

Oscillatoria limosa C. Agardh ex Gomont 1892 متعلق به تيره Oscillatoriaceae، راسـته Oscillatoriales، رده Cyanophyceae است. در سرده Oscillatoria تال معمولا

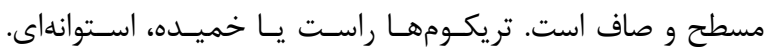

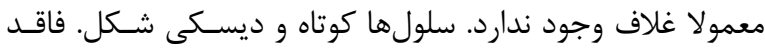
اكينت و هتروسيت. صفات تشخيصى عبارتند از: ابعـاد تريكـوم و

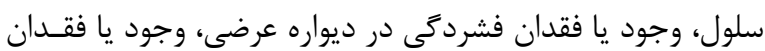

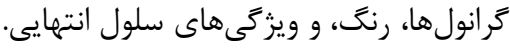

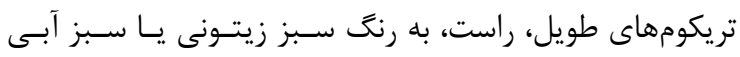

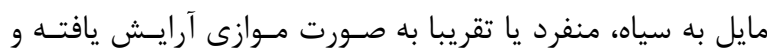
تشكيل توده مى دهند. تريكوم در انتها باريـك نشـده يـا در انتهـا

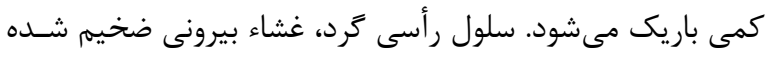

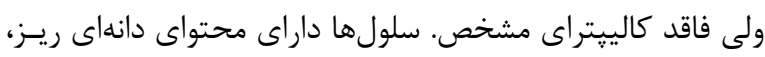

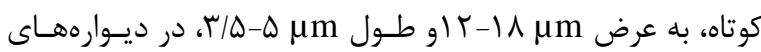

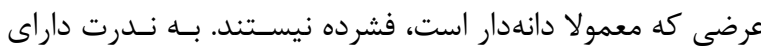

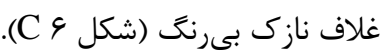
يراكنش در منطقه مورد مطالعه: بنتيك. به شـكل تـوده لـزج بـازي روى سطح سوبسترا در ايستكاههاى رودخانه باليخلو.

Oscillatoria princeps Vaucher ex Gomont 1892

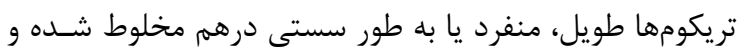

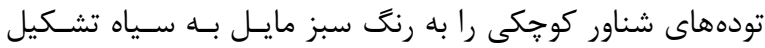

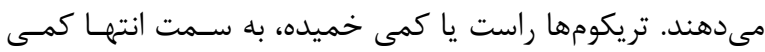

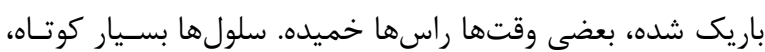

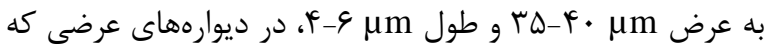

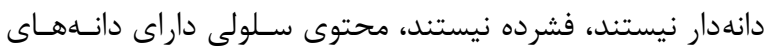

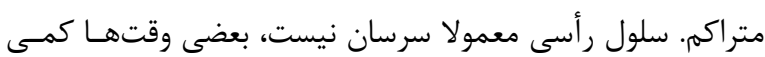
سرسان است، غشاء بيرونى محدب و صاف (شكل F F F).

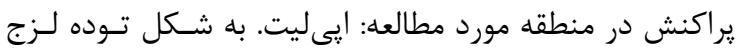
روى سطح سوبسترا در ايستخاههاى رودخانه باليخلو.

\section{Oscillatoria tenuis C. Agardh ex Gomont} تريكومها به رنگ سبز آبى روشن، راست يا كمى انعطاف يـــير.

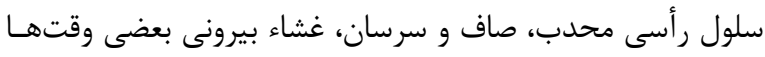

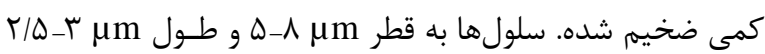

در ديوارههاى عرضى كه دانهدار هستند، فشرده (شكل 4 (D).

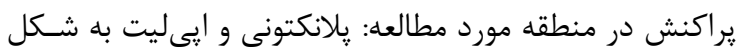

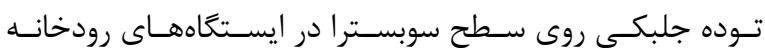
باليخلو.

Planktolyngbya limnetica (Lemmermann) Komarkova-Legnrova \& Cronberg 1992

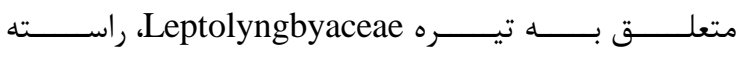

Synechocooccales 


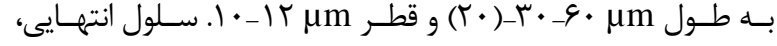
طويل و حنبدى شكل است. يلاستها حاشيهاى. مونواسـيورانزها روى انشعابات جانبى كوتاه ينجهاى از سلولهاى نيمهدلتوئيدى قرار دارند.

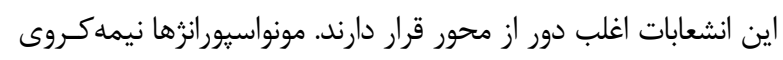

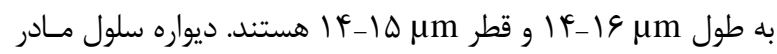
ياياست (شكل (D C V). يــراكنش در منطقـهـ مــورد مطالعـه: بــه صـورت ايسىليـت در ايستخاههاى رودخانه باليخلو.

بحث

به طور كلى در اين بررسى \| آرايه جلبكى شناسـايى كرديـد

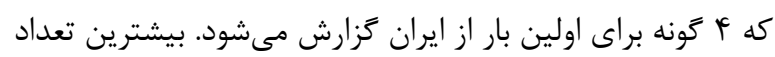

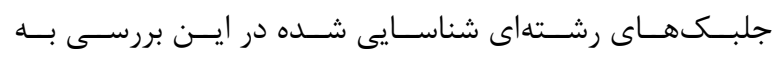

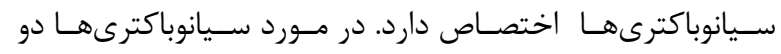

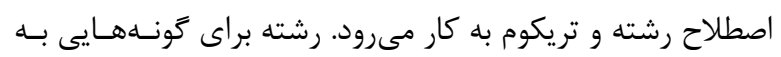

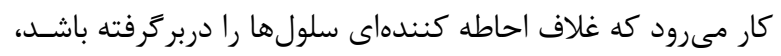
اما براى آرايش خطى سلولها بدون غلاف احاطه كننده، اصطلاح تريكوم بـه كـار مسىرود (Bellinger \& Sigee, 2010). امـا در منابع مختلف كاهى اين دو اصطلاح معادل هم به كـار مسىرود. از

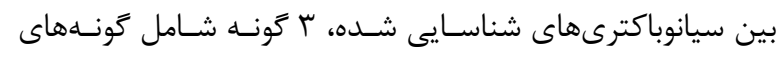
Homoeothrix janthina Arthrospira gigantea Tychonema bourrellyi آرايهشناسى و نامخـذارى دو سـرده Arthrospira و Spirulina كه از نظر ريختشناسى خيلى شبيه هم هستند، تقريبا كل قـرن

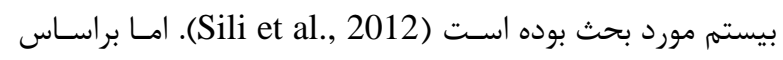
كليدى كه Castenholz در سال I ل . ب ارائه داد اين دو سرده را

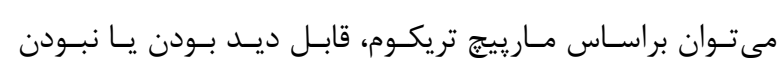

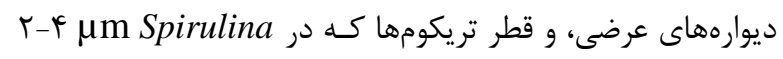
و در د I Mm Arthrospira

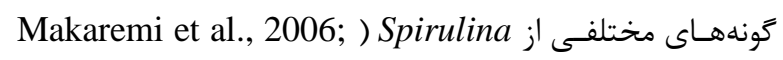
Masoudi ) Arthrospira Zarei Darki, 2011 (et al., 2012

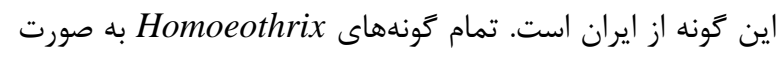

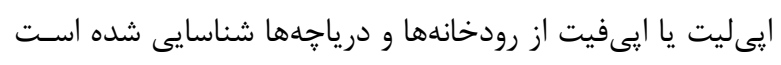
(Wehr \& Sheat, 2003)

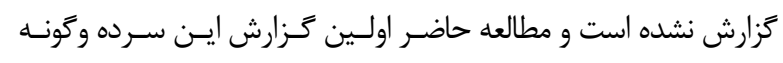
Homoeothrix janthina رودخانه باليخلو شناسايى شـد. از سـرده Tychonema در مجمـوع 1 زونه شناسايى شده است كه تنها دو گونه آن معروف است كه يكى از
سلولى نازك، كلرويلاستها متعدد (ه-1 ())، غالبا ديسكى شـكل

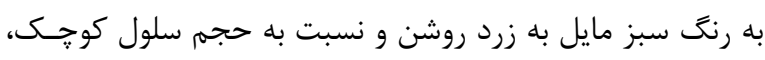

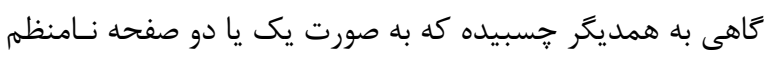

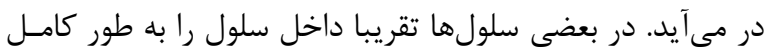

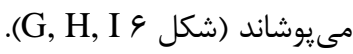
يراكنش در منطقه مورد مطالعه: از تمام سوبستراهاى ايسـتخاه اول رودخانه كه سرعت جريان آب كم بود، مشاهده شد. Vaucheria sp. متعلق به تيره Vaucheriaceae، راسـته Vaucheriales، رده Xanthophyceae

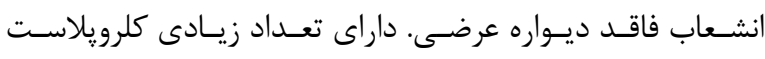

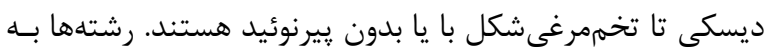

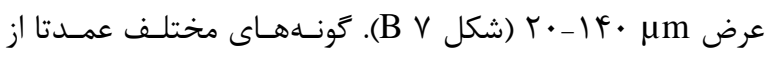
روى ساختارهاى توليدمثلىشان شناسايى مىشوند ( Bellinger

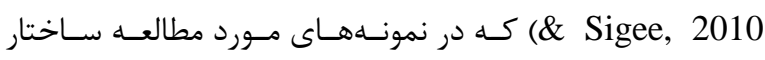
توليدمثلى مشاهده نشد. اين جلبك بسيار متداول است و معمولا

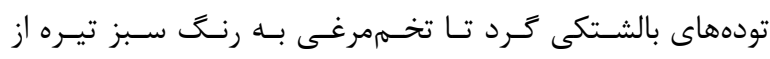

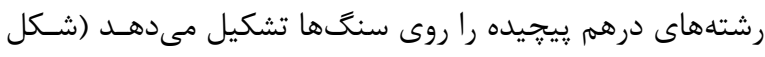

يراكنش در منطقه مورد مطالعه: ايىليت، يا همراه با گونههـاى Cladophora Spirogyra رودخانه كه جريان آب كم بود، تشكيل داده بود.

\section{شاخه Rhodophyta}

Audouinella eugenea (Skuja) C-. C. Jao

Syn: Chantransia eugenea Skuja

Pseudochantransia eugenea (Skuja) F.D.Ott

اين گَونه به عنوان زَزارش جديدى بـراى ايـران در ايـن مقالـه

$$
\text { ذكر مى شود. }
$$

متعلق به تيره Acrochaetiaceae، راسـته Acrochaetiales،

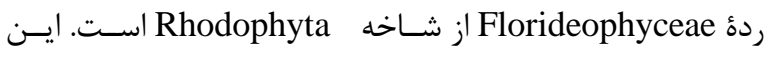
سرده از رشتههاى كوتاه منشعب يكـرديفى تشكيل شـده اسـت.

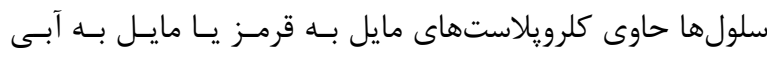

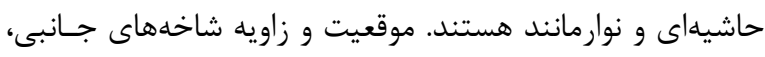

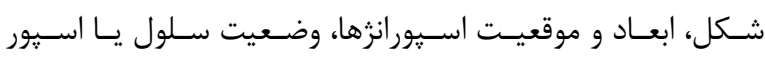

قاعدهاى از صفات مهرم تشخيصى گونههاى اين سرده هستند.

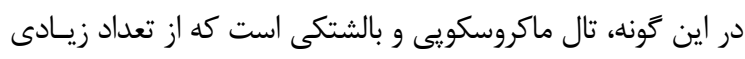
رشتههاى منشعب يكرديفى از يك قاعده ريزوئيدى فشرده تشـكيل

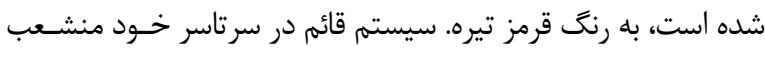

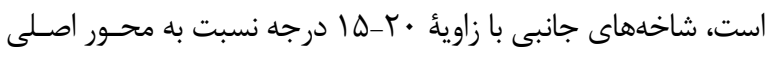
تشكيل مىشوند اما به عقب انحنا مىيابند تا كمابيش مــوازى شـوند.

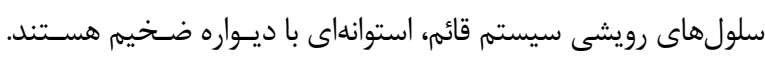



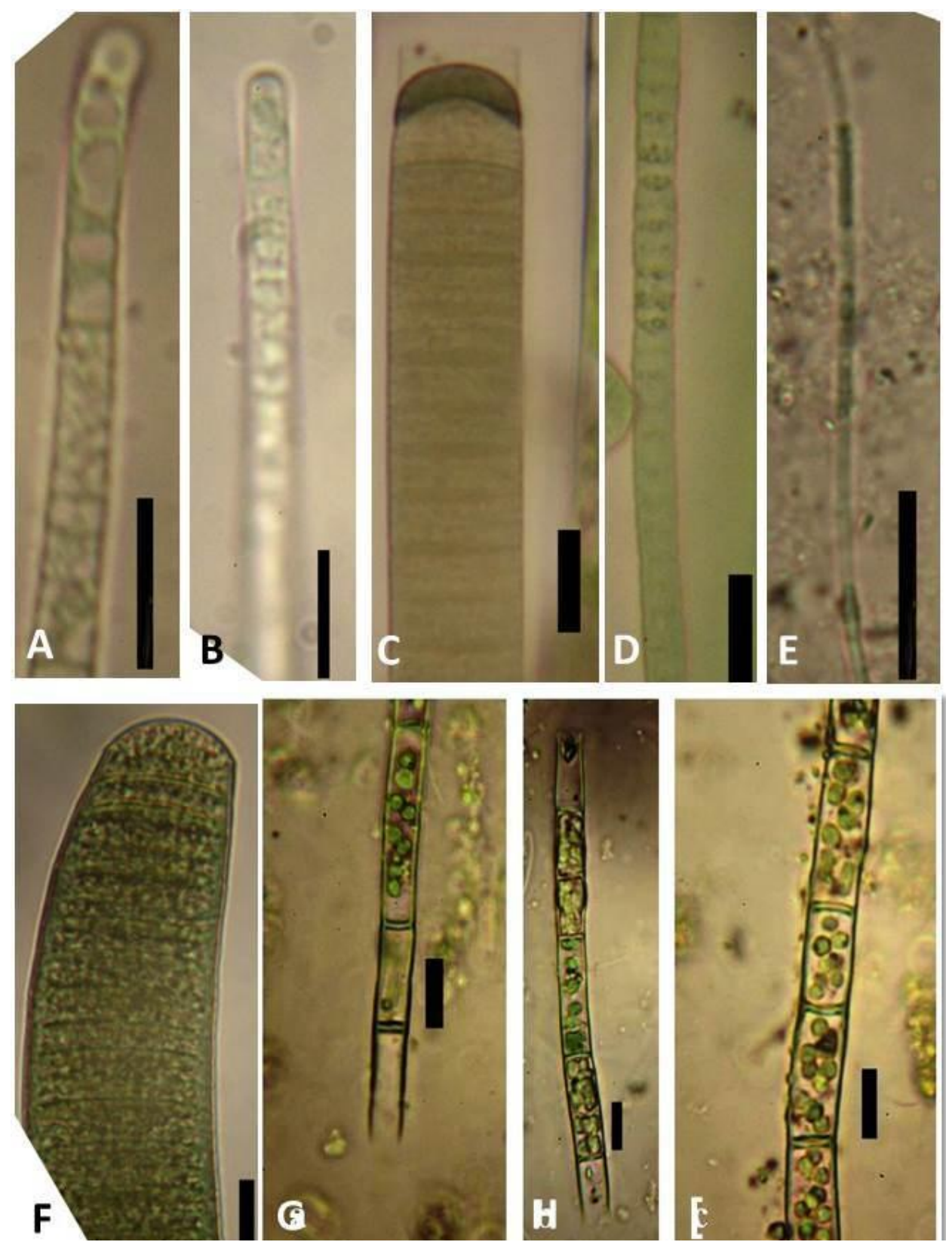

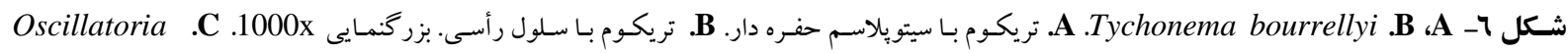

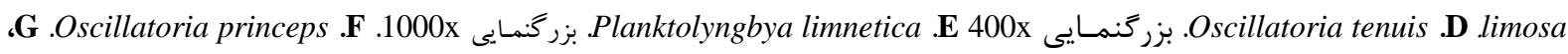

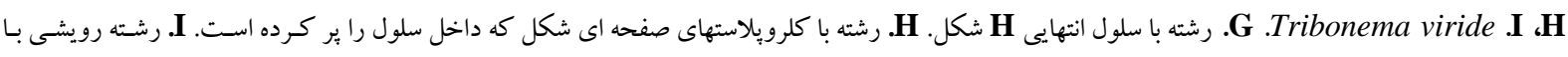

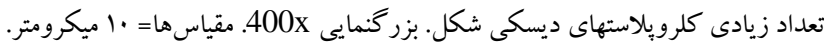

Fig. 6. A, B. Tychonema bourrellyi. A. Trichome with keritomized Cytoplasm. B. Trichome with apical cell. Magnification 1000x. C. Oscillatoria limosa. D. Oscillatoria tenuis. Magnification 400x. E. Planktolyngbya limnetica. Magnification 1000x. F. Oscillatoria princeps. G, H, I. Tribonema viride. G. Trichome with H shape end cell. H. Trichome with plate like chloroplasts filling inside the cell. I. vegetative filament with numerous disk shape chloroplasts. Magnification 400x. Bars $=10 \mathrm{~m}$. 

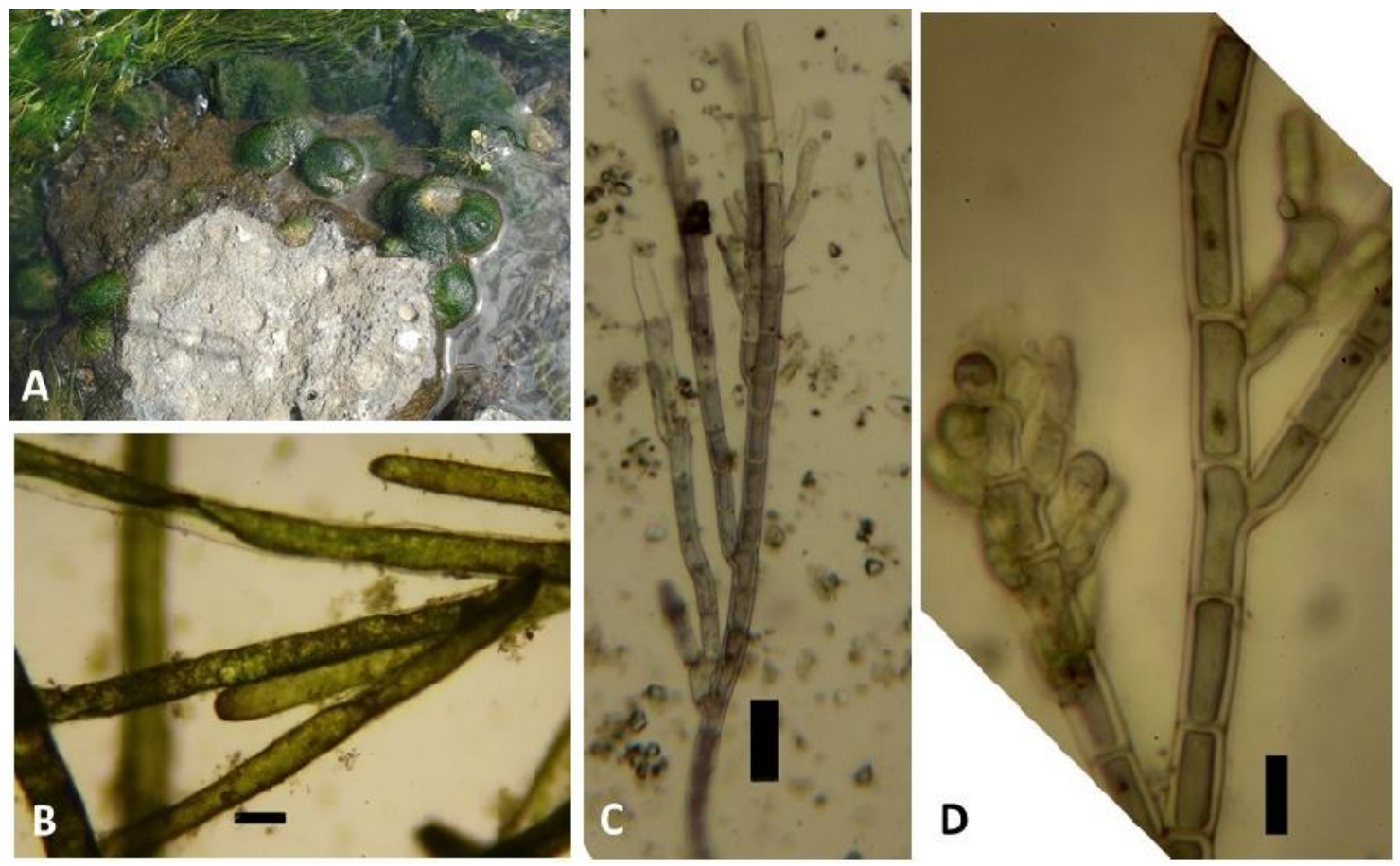

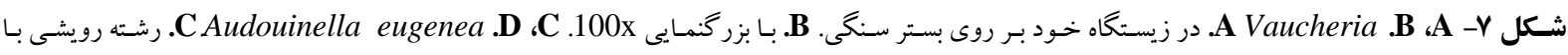

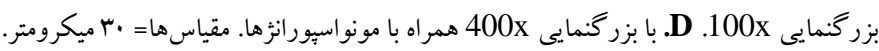

Fig. 7. A, B. Vaucheria. A. in its habitat on the stony substrate. B. with magnification of 100x. C, D. Audouinella eugenea. C. vegetative filament with magnification of 100x. D. with magnification of 400x with monosporangs. Bars= $30 \mathrm{~m}$.

Planktolyngbya رده كـهـ از ســد يـامجى شناسـايى خرديــد limnetica

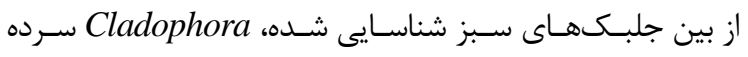

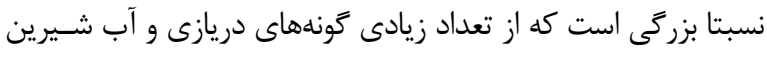

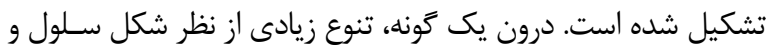

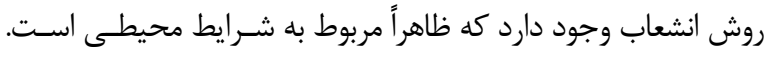

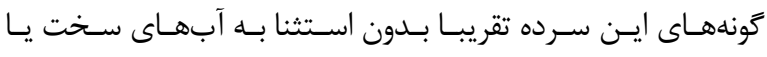

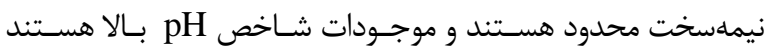

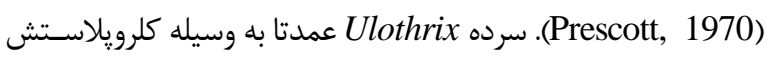

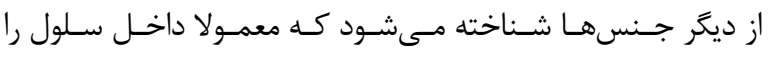

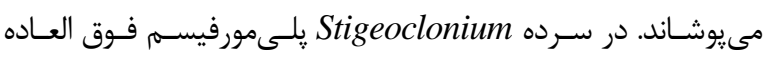

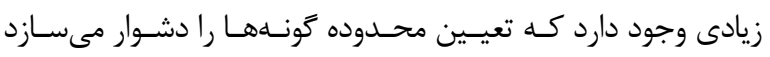

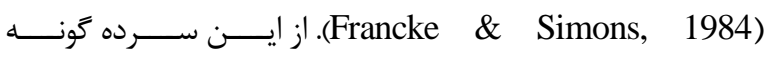

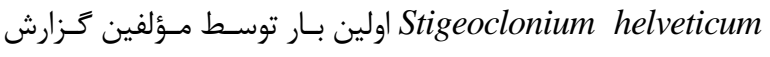

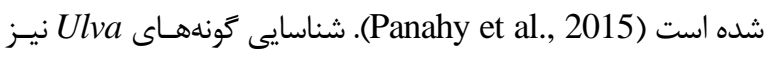
مشكل بوده و علاوه بـر ريخـتشناسـى براسـاس آرايـش و جزئيسات

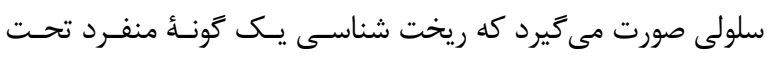

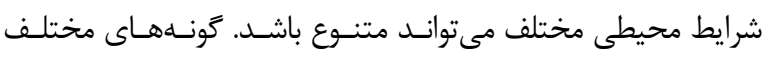

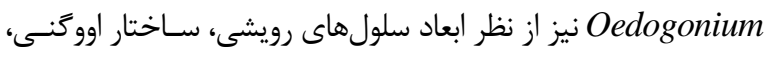

آنها گَونه، Tychonema bourrellyi است كه يك گَونه بֶلانكتـونى

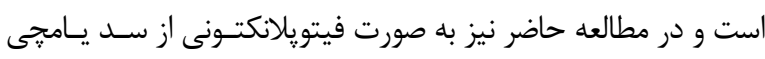

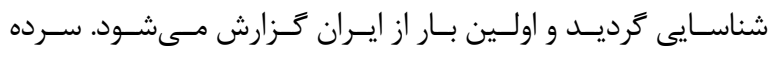
يscillatoria

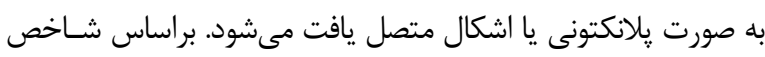

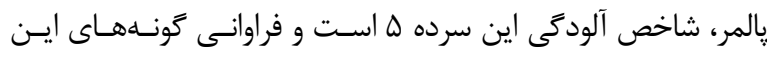

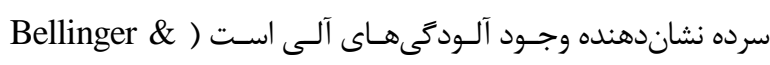

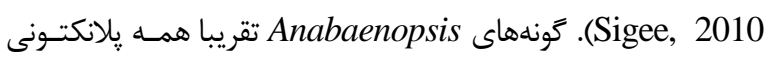

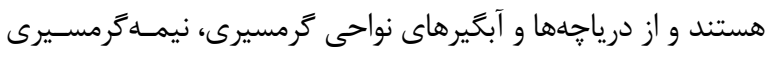

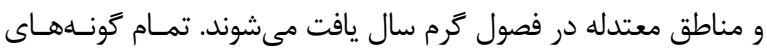

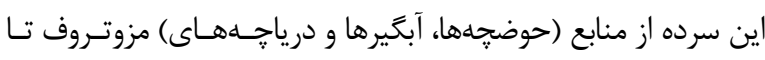

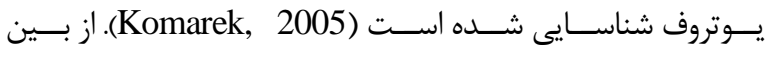
سيانوباكترىهاى موجود در ايـن مطالعـ،

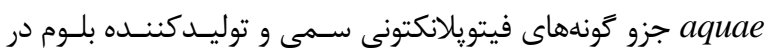

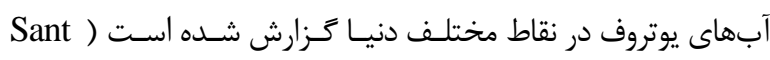
Anna \& Azevedo, 2000; Wehr \& Sheath, 2003

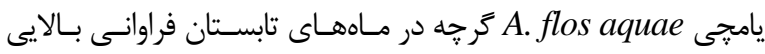

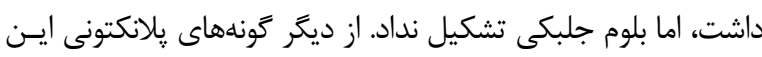




\section{REFERENCES}

Bellinger, E.G. \& Sigee, D.C. 2010. Freshwater algae, identification and use as bioindicators. WileyBlackwell, $271 \mathrm{pp}$.

Bilgrami, K.S. \& Saha, L.C. 2002. A textbook of algae. CBS publishers \& distributors, India, 260 pp.

Castenholz, R.W. 2001. Form-genus I Arthrospira Stizenberger 1852. In: Boone, D.R., Castenholz, R.W., Garrity, G.M. (eds.), Bergey's manual of systematic bacteriology; vol $1,2^{\text {nd }}$ ed. Springer, New York, pp 542-543.

Compere, P. 1981. Algues des déserts d'Iran. Bulletin de Jardin Botanique Nationale de Belgique 51: 3- 40.

Crossdale, H. 1973. Freshwater algae of Ellesmere Island. National Museum of Natural Sciences, Ottawa.

Faghir, M.B. \& Shafii, S. 2013. Floristic study on the algae of Siahdarvishan River in Guilan Province, North Iran. Caspian Journal of Environmental Science 11: 111-126.

Francke, J.A. \& Simons, J. 1984. Morphology and systematic of Stigeoclonium Kütz. (Chaetophorales. In Irvine, D.E.G. and John, D.M. (eds.), Systematics of the green algae. Academic Press, London, pp. 363 377.

Gonzales, A.C. \& Gnzalez, A.M. 2010. Notas sobre algunas algas y Cinaoprocariotas dulciacuicolas de Cuba. Algas 43: 6-10.

Guiry, M. D. \& Guiry, G.M. 2018. AlgaeBase. Worldwide electronic publication, National University of Ireland, Galway. http://www.algae base.org.

Hirano, M. 1973. Freshwater algae from Mesopotamia. Contributions Biol. Lab. Kyoto Univ. 24: 105-119.

Ioriya, T. 1986. Taxonomic studies of the genus Tribonema (Xanthophyceae, Chrysophyta) from Japan. J. Tokyo Univ. Fisheries 73: 1-47.

John, D.M., Whitton, B.A. \& Brook, A.J. 2005. The Freshwater algal flora of the British Isles, An identification guide to freshwater and terrestrial algae. Cambridge University Press. 702 pp.

Komarek, J. 2005. Phenotype diversity of the heterocytous cyanoprokaryotic genus Anabaenopsis. Czech Phycology, Olomouc 5: 1-35.

Lokhorst, G.M. 2003. The genus Tribonema (Xanthophyceae) in the Netherlands. An integrated field and culture study. Nova Hedwigia 77: 19-53.

Makaremi. M., Sabkara, J. \& Mohammadjani, T. 2006. Phytoplankton species in Anzali lagoon and Caspian Sea coastal waters. Iranian Scientific Fisheries Journal 15: 129-150.

Masoudi, M., Ramezannejad Ghadi, R. \& Riahi, H. 2012. Phytoplankton flora of Miankaleh wetland. Iranian Journal of Botany 18: 141-148. Tehran.

Messyasz, B. \& Rybak, A. 2008. Macroalgal Ulva intestinalis (L.) occurrence in freshwater ecosystems of Poland: a new locality in wielkopolska. Teka Kom. Ochr. Kszt. Srod. Przyr. OLPAN 5: 126-135.

Michetti, K.M., Leonardi, P. \& Caceres, E.J. 2010. Morphology, cytology and taxonomic remarks of four species of Stigeoclonium (Chaetophorales, Chlorophyceae) from Argentina. Phycological Research 58: 35- 43.

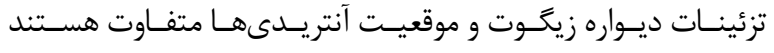

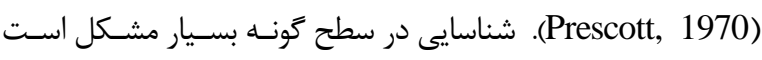

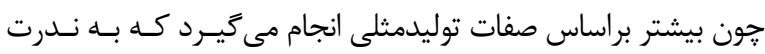

$$
\text { اين جلبك را در شرايط توليدمثلى مىتوان جمعآورى كرد. }
$$

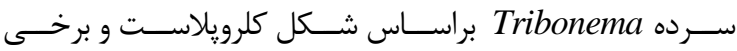

جنبههاى توليدمثلى تعريف شـده اسـت (Lokhorst, 2003). ايسن

سرده از نظر داشتن قطعات H شـكل در ديـوارهشـان، شـبيه سـرده Microspora اين دو سرده را بهراحتى مىتوان با كلرويلاستهاى ديسكى شكل بـه

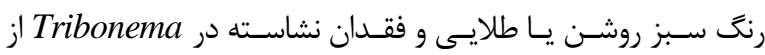
همديگر تشخيص داد (Wehr \& Sheat, 2003).

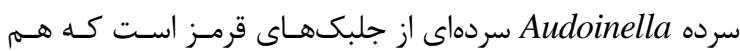

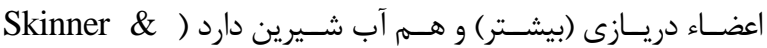
A. eugenea .Entwisle, 2001

$$
\text { از اين رودخانه است كه براى اولين بار از ايران زَارش مىشود. }
$$

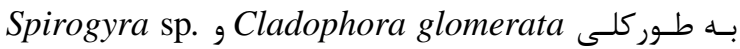

Spirogyra sp. فراوانترين آرايههاى موجود در منطقه هسـتـند يك سرده معمول و فراوان در آبهاى جارى است و از نظر تعـداد

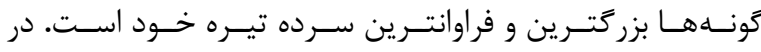
ايستخاههايى با سرعت جريان كم تشـكيل تـودههـايى همـراه بـا

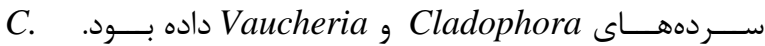
glomerata شيرين سراسر دنياست. اين جلبـك نيازمنـد يـك سـطح سـخت

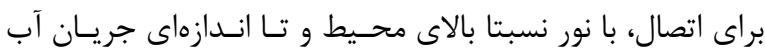

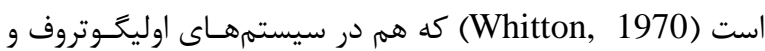
هم يوتروف مى تواند وجود داشته باشد، ولى رشد بيش از حـد آن

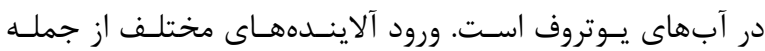

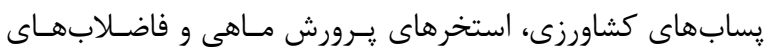

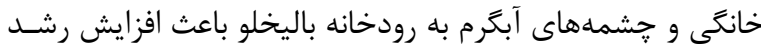

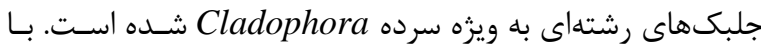
توجه به اينكه آب اين رودخانه به مصـرف شـرب مسىرسـد، بايـد

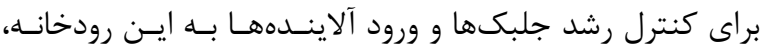

$$
\text { تمهيداتى انديشيده شود. }
$$

$$
\text { سباسگز ارى }
$$

نَارندكًان مراتب قدردانى خود را از شركت سـهامى آب منطقـهاى

$$
\text { اردبيل و آزمايشگاه كاوشگران طبيعت ياك اعلام مىدارند. }
$$


Noroozi, M., Naqinezhad, A. \& Mehrvarz, SH.S. 2009. Algal flora in first Iranian land-marine the Boujagh national park. International Journal of Algae 11: 276288.

Panahy Mirzahasanlou, J., Ramezanpour, Z., Nejadsattari, T., Imanpour Namin, J. \& Asri Younes. 2015. Stigeoclonium helveticum from Balikhli Cahy of Ardabil Province, Iran. VISI Jurnal Akademic 6: 95- 101.

Prescott, G.W. 1970. Algae of the western great lakes area. W.M.C. Brown company publishers, Iowa. 977 pp.

Sant Anna, C.L. \& Azevedo, M.T.P. 2000. Contribution to the knowledge of potentially toxic cyanobacteria from Brazil. Nova Hedwigia 71: 359-385.

Sili, C., Torzillo, G. \& Vonshak, A. 2012. Arthrospira (Spirulina). In Whitton, B.A. (ed.). Ecology of Cyanobacteria II: Their diversity in space and time. Springer Science + Business Media B.V, 760 pp.

Skinner, S. \& Entwisle, T.J. 2001. Non- marine algae of Australia: 3. Audouinella and Balbiania (Rhodophyta). Telopea 9: 713-723.
Skinner, S. \& Entwisle, T.J. 2004. Non marine algae of Australia: macroscopic Chaetophoraceae (Chaetophorales, Chlorophyta). Telopea 10: 613-33.

Tiffany, L.H. \& Britton, M.E. 1971. The algae of Illinois. Hafner Publishing Company, New York, 704 pp.

Wasylik, K. 1975. Notes on the freshwater algae of Iran. Fragm. Florist. Geobot 3: 369-396.

Wehr, J.D. \& Sheath, R.G. 2003. Freshwater algae of North America, ecology and classification. Academic Press. 918 pp.

Whitton, B. A. 1970. Biology of Cladophora in freshwaters. Water Resources 4: 457-76.

Zarei Darki, B. 2011. Algae of aquatic ecosystems of Iran. Payam-e-Alavi Press. 323 pp.

Zarei Darki, B., Zarei Darki, L., Akkafi, H.R. \& Mirzai, M. 2013. Taxonomic composition of algae and its indicator role in the ecosystem of the Zayandehrud River, Iran. Inland Water Biology 6: 285-293.

How to cite this article:

Panahy Mirzahasnlou, J., Nejadsattari, T., Ramezanpour, Z., Imanpour Namin, J. \& Asri, Y. 2020. Identification of filamentous algae of the Balikhli River in Ardabil province and recording four new species for algal flora of Iran. Nova Biologica Reperta 7: 331-345. (In Persian).

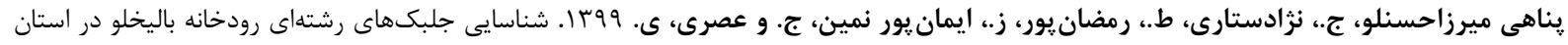

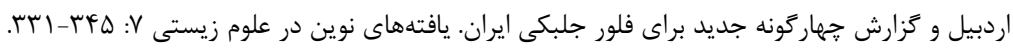

